\section{Perception of psychiatry by the media and by patients}

DEAR Sirs

I read with interest Dr Peter Haddad's article in the Bulletin (Haddad, 1991) about the portrayal of psychiatrists in films, and I would like to comment on his conclusions, because I think they have an important bearing on the education of psychiatrists.

Dr Haddad gives some vivid sketches of the terrifying figures depicted as evil psychiatrists, and points out the power that such images can have in the minds of anyone-especially, of course, mentally disturbed people, whose perception of the psychiatrist facing them may be greatly influenced. "However, the fact remains that Dr Evil is a gross misrepresentation of the average psychiatrist", he adds.

He goes on to express regret that "this stereotype may prejudice public opinion", and might make patients "more likely to incorporate psychiatric staff into their persecutory delusions; the negative effects on treatment are obvious."

It seems to me that these remarks reflect an idea about the psychotic individual which, put simply, is that he or she has irrational beliefs about the psychiatrist (and/or the nursing staff) and has to be shown that they are false. "You are wrong about me," a psychiatrist might say. "I intend you no harm, and your suspicions are a proof that you are out of touch with reality. But take these drugs which I offer you, and you will come to perceive me and others as we really are not at all the sinister figures you accuse us of being".

I know very well, from many years work in psychiatry, that such an idea would frequently be the basis of a response to a psychotic patient. But would not today's registrars be encouraged to consider other possibilities? In particular, far from regretting as negative the possibility that a patient might "incorporate psychiatric staff into their persecutory delusions", might this not form the basis for an attempt to understand the meaning of the patient's delusions, accepting the relationship he/she imposes as a means to doing so? I don't of course mean pretending to agree with the patient - (something I have seen attempted in desperation) but being prepared to treat what the patient says as meaningful, and even perhaps, in some way, true.

Perhaps this is asking a lot; it means spending much more time with psychotic patients, and it involves the psychiatrist (or nurse) in very stressful situations. I might well have dismissed the idea of writing this letter had it not been for rather an odd coincidence. In the same issue of the Bulletin, Pourgourides \& Oyebode (1991) write about the psychopathology of the double, as presented in a novel, whose central character is a man named Suguro. He is accused of very serious misdeeds, which he sincerely denies, attributing them to an elusive shadowy double who "is everything that (the real) Suguro is not, and the achievements of a lifetime are threatened by the reports of unacceptable behaviour ascribed to this "double'." Needless to say, his 'double' represents the disowned parts of himself which he must come to accept, enduring a great deal of pain in the process.

It is interesting to put those two communications together. Is any psychiatrist (let alone "an average' one) completely devoid of the enjoyment of power? In our profession, power over people's minds and bodies is available, and has sometimes been dreadfully abused. If we never provide opportunities for trainees to experience themselves as the embodiment of imagined persecutors, there can be at least two regrettable consequences. The first is that the patient may never discover who "really were" the accuser and accused, and have to accept that he was simply mistaken - or wrong - or mad; hoping that the drugs he is given will seal off a part of his mind. The second is that the psychiatrist may never recognise his double in the patient's delusions.

To make another parallel, it is as though the problem raised for psychiatrists by representations of " $\mathrm{Dr}$ Evil" could be solved by suppressing the films and videos etc. I am suggesting rather that we make them the object of serious study, whether on a screen or in the consulting room.

\section{Hangleton Manor Close Hove, Sussex BN3 8AJ}

ERNEST BRAM

\section{References}

HADDAD, P. 1991 The 'evil' psychiatrist and modern cinema. Psychiatric Bulletin, 15, 652-653.

Pourgourides, C. \& OYerode, F. Psychopathology of the double. Psychiatric Bulletin, 15, 642.

\section{Dear Sirs}

It was with interest that we read Dr Haddad's article on the media's perception of psychiatry and psychiatrists (Psychiatric Bulletin, 1991, 15, 652-653). It would appear that the stigma surrounding mental health problems is still a potent force despite the increasing emphasis on community care.

In this connection we have looked at psychiatric out-patient attendances at a local district general hospital (DGH) and a nearby psychiatric hospital in Swansea. We identified all new referrals, from 1 February to 31 August 1991, made to four consultants in adult psychiatry who hold clinics at both the local DGH and their base at Cefn Coed Hospital $(\mathrm{CCH})$. We had compared the rates of nonattendance for new cases at these clinics and in doing so have assumed that there should be no difference.

Of 194 cases due to be seen at the DGH, $63(32 \%)$ did not attend; of 279 cases due to be seen at $\mathrm{CCH}$, 